\title{
Nest success and parental investment in the Critically Endangered Maui parrotbill Pseudonestor xanthophrys with implications for recovery
}

\author{
C. Dustin Becker ${ }^{1, *}$, Hanna L. Mounce ${ }^{1}$, Tonya A. Rassmussen ${ }^{1,3}$, \\ Anna Rauch-Sasseen ${ }^{1,4}$, Kirsty J. Swinnerton ${ }^{1,5}$, David L. Leonard ${ }^{2}$ \\ ${ }^{1}$ Maui Forest Bird Recovery Project, Makawao, Hawaii, USA \\ ${ }^{2}$ Hawaii Department of Land and Natural Resources, Division of Forestry and Wildlife, Honolulu, Hawaii, USA \\ ${ }^{3}$ Present address: 863 Mockingbird Dr., College Place, Washington 99324, USA \\ ${ }^{4}$ Present address: 422 Ocean Blvd. North, Longbranch, New Jersey 07740, USA \\ ${ }^{5}$ Present address: Island Conservation Canada, Kelowna, British Columbia, Canada
}

\begin{abstract}
The Critically Endangered (IUCN) Maui parrotbill Pseudonestor xanthophrys, an endemic Hawaiian honeycreeper, is restricted to a single population of about 500 individuals. During 3 breeding seasons (2006 to 2008) we found and monitored 17 Maui parrotbill nests from 13 pairs. Eggs and incubating females were confirmed for 12 of the nests, but only 4 fledged successfully. Severe weather led to nest abandonment in 5 cases. Two nests were depredated, and 1 nest had an egg that failed to hatch. Three pairs renested after failures. We used logistic linear regression and ANOVA to evaluate $300 \mathrm{~h}$ of observations to assess the effects of parental investment behavior and weather on nest fate. Female time incubating, a significant factor explaining nest fate, did not differ by time of day, but averaged $12 \mathrm{~min}^{-1}$ less for failed than for successful nests. Male provisioning rates to adult females and chick feeding rates by parents were also significantly related to nest success. Male vocalizations near the nest did not differ by nest fate. Establishment of a second population is a key step in the recovery of Maui parrotbills, and a small captive population has been established. Although limited, our data suggest that collection of Maui parrotbill eggs and/or nestlings up to $1 \mathrm{wk}$ old from nests for captive rearing, especially in advance of severe winter storms, would have minimal effects on the population.
\end{abstract}

KEY WORDS: Maui parrotbill $\cdot$ Avian ecology $\cdot$ Parental investment $\cdot$ Endangered birds

\section{INTRODUCTION}

An understanding of animal behavior can play an important role in the conservation and recovery of endangered species (Pärt \& Doligez 2003, Swaisgood 2007, Stamps \& Swaisgood 2007). For example, knowing age-related survival rates and behavior related to successful recruitment are important for recovery planning. The small population size of many endangered species and the potential need to establish new populations via translocation of wild individuals or release of captive bred individuals requires that effects on donor populations are minimized while successful recruitment is maximized.

The Maui parrotbill Pseudonestor xanthophrys is a Hawaiian honeycreeper representing a monotypic genus listed as endangered under the US Endangered Species Act (US Fish and Wildlife Service 2006) and as Critically Endangered by the IUCN (see www.iucnredlist.org/apps/redlist/details/149614/0 and arkive.org/maui-parrotbill/pseudonestor-xanthophrys/). Maui parrotbills are estimated at $502( \pm 116 \mathrm{SE})$ indi- 
viduals and are restricted to about $50 \mathrm{~km}^{2}$ of highelevation rain forest on windward east Maui (Scott et al. 1986, USFWS 2006). They exhibit prolonged parental care, defend relatively large areas, specialize in extraction of insects from dead wood, and typically produce only a single offspring each year (Simon et al. 2000). These birds form long-term monogamous pair bonds which are reinforced by male to female feeding during courtship, incubation, and brooding and prolonged care of fledglings for up to 17 mo (Simon et al. 1997, 2000, Maui Forest Bird Recovery Project (MFBRP) unpubl. data). Only the females incubate and brood, and they depend on male provisioning while nesting. Severe weather is thought to be a major cause of nest failure (Simon et al. 1997).

The recovery plan for Maui parrotbills includes the establishment of a second population on the leeward side of Maui, and captive propagation is expected to play a role in this effort (USFWS 2006). The Hawaii Endangered Bird Conservation Program (HEBCP) of the San Diego Zoo's Institute for Conservation Research has made notable progress breeding Hawaiian passerines in captivity (Kuehler et al. 1996, Tweed et al. 2006). Since the captive breeding program's inception in 1993, 18 Maui parrotbill eggs have been successfully incubated and hatched, and 15 have been reared to independence. In one case, Maui parrotbills have bred to the second generation. However, infertility caused by pair incompatibility and lack of synchrony in reproductive readiness between paired males and females appears to be slowing production (A. Lieberman, R. Switzer, and A. Poopatanapong pers. comm.).

The influence of parental behavior on nest success has not been studied in Maui parrotbills. Understanding behavior correlated with nest failure may help structure the timing of egg and nestling collection for captive breeding such that the effects to the donor population are minimized. Wild parental behavior may also shed some light on pair quality and compatibility in captivity and for translocations. Evaluation of male vocalization during the breeding season can assist with design of aural environments in captive and translocation settings (Schlossberg \& Ward 2004). Here, we report on how variation in parental behavior and weather affect nest fate in the federally endangered Maui parrotbill.

\section{MATERIALS AND METHODS}

Study area. The Hanawi Natural Area Reserve on windward east Maui covers 3036 ha. Above $1600 \mathrm{~m}$ the reserve is fenced and ungulate free. The area is steep, regularly dissected by ridges and gulches, and supports montane wet forest dominated by 'ohi`a Met- rosideros polymorpha and olapa Cheirodendron trigynum. For additional information see Jacobi \& Scott (1985) and Simon et al. (2000). Since 1995, the MFBRP has worked at 2 study sites at Hanawi (Fig. 1). The Home Range 3 (HR3) site is 35 ha between 1600 and $2000 \mathrm{~m}$ elevation and is treated to reduce rodent numbers (Malcolm et al. 2008). The Frisbee (FSB) site is 70 ha between 1600 and $2200 \mathrm{~m}$ elevation and has no rodent reduction treatment.

Data collection. During January through May 2006 to 2008,8 to 10 biologists searched for Maui parrotbill nests. Once a nest was discovered, the site was visited daily until fledging or nest failure occurred. When incubation behavior was confirmed, nests were observed more intensively during $3 \mathrm{~h}$ sampling periods from blinds located at least $30 \mathrm{~m}$ from the nest tree using spotting scopes (20 to $60 \times$ ). The sex of parents was determined by color bands, behavior, vocalizations, and physical characteristics (Simon et al. 1997); most birds were uniquely marked. We estimated egg and nestling ages based on a $16 \mathrm{~d}$ incubation period and a $20 \mathrm{~d}$ nestling period (Simon et al. 1997). We assigned nestlings to 2 groups - first week ( 1 to $7 \mathrm{~d}$ ) and late hatchling (8 to $20 \mathrm{~d}$ ) - based on chick development and thermoregulatory capacity (Simon et al. 1997).

Nest stage (i.e. incubating, nestling, fledgling) was recorded at the start of each observation period, and

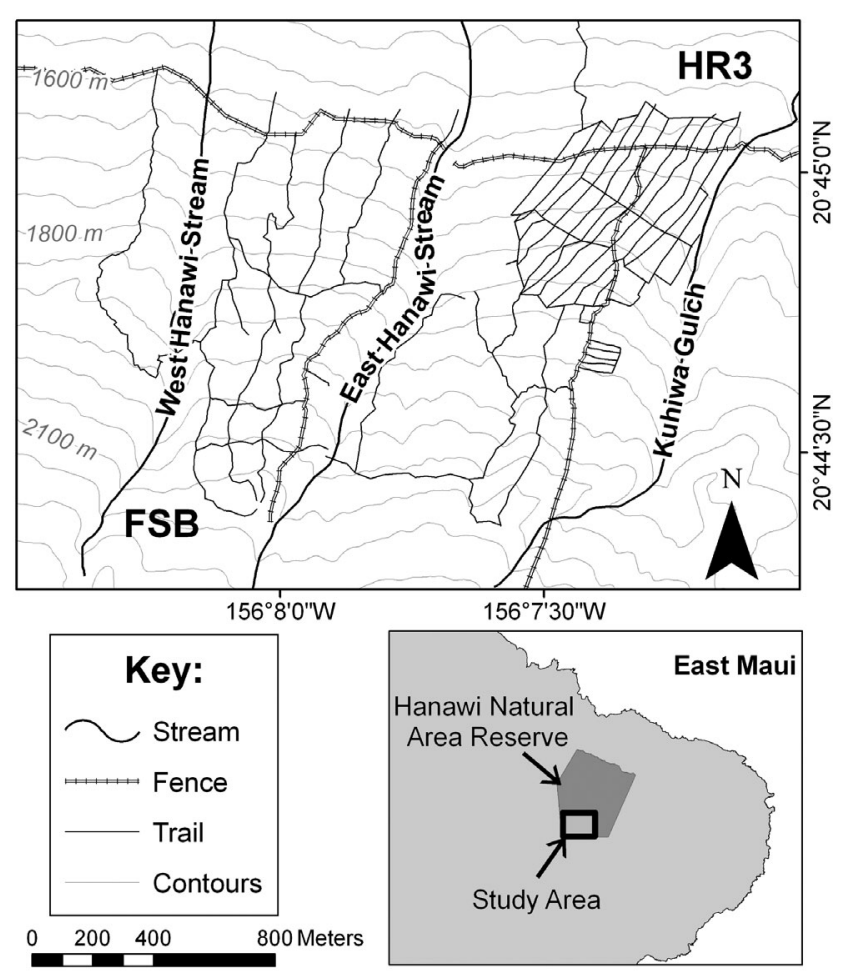

Fig. 1. East Maui study area showing Frisbee (FSB) and Home Range 3 (HR3) sites in the Hanawi Natural Area Reserve on the northeastern slopes of Haleakala volcano, Hawaii 
ambient weather (percent cloud cover, rain score, and wind score on the Beaufort scale) was recorded each hour. We recorded times and durations of parental behavior at and around the nest and nest tree. Parental investment was quantified using 4 metrics: (1) percent time females spent on nests incubating or brooding (i.e. female investment); (2) per hour feeding rates of females by males (i.e. male investment); (3) per hour feeding rates of nestlings by both parents (i.e. parental investment); and (4) per hour song rates by males near or at the nest (i.e. male attentiveness). We conducted observations during all daylight hours from sunrise (06:00 h) to sunset (18:00 h), and attempted to obtain at least 4 observation periods at each nest during incubation and nestling stages.

Statistical analysis. Observations were categorized into time of day intervals as follows: early morning (06:00 to $10: 00 \mathrm{~h})$, mid-day (10:00 to $15: 00 \mathrm{~h})$, and late afternoon (15:00 to 18:00 h). We defined successful nests as those producing a fledgling. We used logistic linear regression to relate parental investment to nest fate. Depredated nests were not included in these analyses because they were not abandoned. We used ANOVA to further refine analyses with 3 categories of nest fate (failed, succeeded, and depredated). Extreme values for wind and rain were added together to create a weather severity score for each observation in order to determine if extreme weather over the course of a nesting attempt was predictive of nest fate. All analyses were conducted using JMP statistical software (SAS) and results are presented as means and standard errors.

\section{RESULTS}

Over the 3 breeding seasons, at least 10000 personhours were spent searching for nests; this yielded 17
Maui parrotbill nests from 13 different pairs. Five nests (29\%) were abandoned during construction, and 12 had an egg laid in them. Of the nests with eggs, 5 failed during incubation (33\%) and 3 (17.6\%) failed when nestlings were less than 1 wk old (Table 1). The HR3 site had 11 nests, whereas only 1 nest was found within the FSB site. Nestlings fledged from 4 nests $(25 \%)$; one pair produced 3 of these nests. Of 8 nest failures, 5 occurred during strong storms. Two nests were depredated, one by a short-eared owl Asio flammeus sandwichensis (Mounce 2008) and another was assumed depredated by a rat. At one nest the egg was incubated for $34 \mathrm{~d}$, twice the normal incubation period (Simon et al. 1997), and then abandoned. Three pairs re-nested and 2 were successful. Annual nest success was $50 \%(\mathrm{~N}=2), 17 \%(\mathrm{~N}=6)$, and $50 \%(\mathrm{~N}=4)$ for 2006, 2007, and 2008, respectively.

Data on parental investment and weather were collected at 11 nests ( 7 Maui parrotbill pairs) and totaled 300 person hours. Female investment or the percentage time spent incubating was significantly related to nest success $(p<0.0004)$ and, in combination with the effect of individual female ( $\mathrm{p}<0.0001)$, had an $\mathrm{r}^{2}$ value of 0.50 (whole model test: $\chi^{2}=247, \mathrm{~N}=361$, $\mathrm{df}=11, \mathrm{p}<$ $0.0001)$. Weather was not significant in this model. Over the $16 \mathrm{~d}$ incubation period, female investment in time spent incubating declined from 92.5 to $81 \%$ ( $\mathrm{r}=$ 0.32 , df $=34, \mathrm{p}<0.06$ ), but did not vary significantly by time of day. Female investment varied by nest outcome (ANOVA, $F_{2,105}=4.7, \mathrm{p}<0.011$ ), with failed nests being incubated for less time than successful ones $(t=$ 2.9 , df $=96, \mathrm{p}<0.004)$. At successful nests, females spent $89 \pm 8 \%$ of their time incubating, compared to $69 \pm 29 \%$ at failed nests (Fisher's protected least significant difference [PLSD], $\mathrm{p}<0.001)$; at successful nests females incubated eggs for $12 \mathrm{~min}^{-1}$ more than at failed nests. The female at the depredated nest spent

Table 1. Pseudonestor xanthophrys. Maui parrotbill nests with at least 1 egg at the Hanawi study area (2006-2008). Nest attempt: no. of nesting attempts made by the same pair at the same site; +: yes (produced a fledgling); -: no (failed to produce a fledgling, abandoned, or was depredated)

\begin{tabular}{|lcclcl|}
\hline Site/Nest & Year & $\begin{array}{c}\text { Nest } \\
\text { attempt }\end{array}$ & $\begin{array}{l}\text { Start of incubation } \\
\text { (mm-dd-yy) }\end{array}$ & Success & Last stage observed \& notes \\
\hline HR3-01-06 & 2006 & 1 & $02-17-06$ & + & Fledged, only 2 d of moderately bad weather \\
HR3-03-07 & 2007 & 1 & $03-24-07$ & + & Fledged, bad wind at end, otherwise no severe weather \\
HR3-03-08 & 2008 & 1 & $02-25-08$ & - & Nestling 1st week, severe wind/rain \\
HR3-06-08 & 2008 & 2 & $03-25-08$ & + & Fledged 04-30-08, no severe weather during nesting period \\
HR3-03-06 & 2006 & 1 & $03-29-06$ & - & Nestling 11 d, depredated, severe weather 1st week \\
HR3-02-07 & 2007 & 1 & $02-07-07$ & - & Incubation, abandoned 02-15-07 after severe weather \\
HR3-04-07 & 2007 & 1 & Before 03-29-07 & - & Incubation, high wind at abandonment \\
HR3-06-07 & 2007 & 2 & $05-14-07$ & - & Incubation, severe storm at abandonment \\
HR3-05-07 & 2007 & 1 & $03-29-07$ & - & Nestling, 1st week, severe weather before abandonment \\
FSB-01-07 & 2007 & 1 & $01-21-07$ & - & Incubation, severe storms at time of abandonment \\
HR3-01-08 & 2008 & 1 & $02-19-08$ & - & Incubation, abandoned nest 03-27-08, prolonged incubation \\
HR3-08-08 & 2008 & 2 & $04-09-08$ & + & Fledged 05-13-08, no severe weather during nesting period \\
& & & & &
\end{tabular}




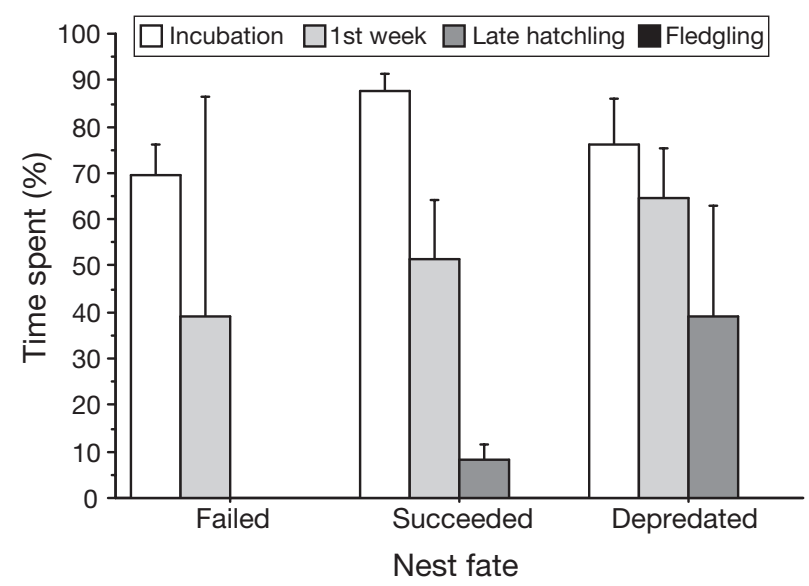

Fig. 2. Pseudonestor xanthophrys. Percentage of time $( \pm \mathrm{SE})$ spent incubating and brooding by female Maui parrotbills by nest fate and nest stage. Sample sizes for nests that failed, succeeded, and were depredated were 4, 7, and 1, respectively

$76 \pm 7 \%$ incubating ( $N=10)$, not significantly different from successful or failed nests (Fig. 2).

During the $20 \mathrm{~d}$ nestling phase, female investment declined, especially after chicks were 8 to $10 \mathrm{~d}$ old. During the first week of brooding, females spent $49 \pm$ $34 \%$ of their time $(\mathrm{N}=35)$ on nests, and this did not differ by nest outcome $(\mathrm{p}<0.58)$. Brooding during the late hatchling period averaged only $12 \pm 2.3 \%$ of a female's time $(\mathrm{N}=51)$. The depredated nest was brooded significantly longer than the other nests during the late hatchling phase (Fisher's PLSD, $\mathrm{p}<0.007$, Fig. 2).

Male provisioning of females on the nest per hour was significant (logistic linear regression, $\mathrm{p}<0.0007$ ) and, when combined with the effect of individual male $(p=$ 0.0001 ), had an $\mathrm{r}^{2}$ value of 0.53 (whole model test, $\chi^{2}=$ $132, N=180, d f=6, p<0.0001$ ). Weather was not significant in this model $(p=0.94)$. Male investment was more frequent during incubation and $1 \mathrm{wk}$ post hatch, about 1 visit every $2 h$, than when nestlings were greater than $1 \mathrm{wk}$ old and after fledging, about 1 visit every $4 \mathrm{~h}$ (ANOVA, $F_{1,3}=15.3, \mathrm{p}<0.0001$ ). There was no difference in male investment at successful versus failed nests (ANOVA, $p<0.5$ ), but the female at the depredated nest received significantly more provisioning visits per hour than other females, even when the age of the nestling was controlled for (Fisher's PLSD, $\mathrm{p}<0.006$; Fig. 3).

Parental investment (feeding nestlings) was significant (logistic linear regression, p < 0.0001) and, when combined with nest stage $(\mathrm{p}=0.0001)$, had an $\mathrm{r}^{2}$ value of 0.90 (whole model test, $\chi^{2}=34.5, \mathrm{~N}=87, \mathrm{df}=4, \mathrm{p}<$ $0.0001)$. Number of feeding trips to the nest varied by nest fate (ANOVA, $F_{2,98}=5.67, \mathrm{p}<0.005$ ). During a nestling's first week, the number of feeding trips to successful nests and the depredated nest was similar $\left(1.1 \pm 0.6\right.$ feeds $\left.\mathrm{h}^{-1}, \mathrm{~N}=96\right)$, whereas at failed nests

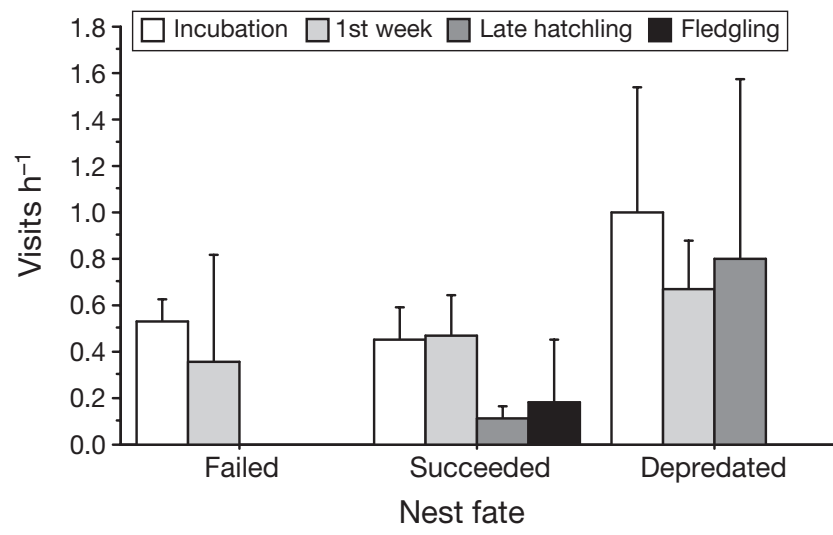

Fig. 3. Pseudonestor xanthophrys. Mean $( \pm \mathrm{SE})$ provisioning visits per hour by male Maui parrotbills to incubating or brooding females by nest fate and nest stage. Sample sizes for nests that failed, succeeded, and were depredated were 4, 7, and 1 , respectively

( $\mathrm{N}=5$ observations) Maui parrotbills delivered food only $0.07 \pm 0.15$ times $^{-1}$ (Fisher's PLSD, $\mathrm{p}<0.001$ ).

Male attentiveness increased substantially with chick development (ANOVA, $F_{1,3}=19.5, \mathrm{p}<0.0001$ ), but was not associated with nest fate $(p=0.38)$. During incubation and when nestlings were less than $1 \mathrm{wk}$ old, male song rates near the nest averaged $1.3 \pm 2$ songs $h^{-1}(N=148)$. When nestlings were older than $1 \mathrm{wk}$ or had recently fledged, song rate increased to $4.5 \pm 4$ songs $^{-1}(\mathrm{~N}=72)$, although there was substantial variation in vocalization rates by individual males.

Weather severity varied by nest stage (incubation, nestling) (ANOVA, $F_{1,183}=14.3, \mathrm{p}=0.0002$ ) and nest outcome $(\mathrm{p}<0.001)$, with significant interactions $(F=3.6, \mathrm{p}=$ $0.03)$. Consistent with the whole model, mean weather severity did not differ for successful versus failed nests during incubation, but was more severe at the depredated nest. During the first week of brooding, the 2 failed nests and the depredated nest experienced higher mean weather severity than successful nests (Fig. 4).

\section{DISCUSSION}

A large suite of environmental factors have been found or are thought to reduce Maui parrotbill productivity in the wild: predation by native and alien vertebrates (Mounce 2008, VanderWerf 2009), restriction to suboptimal habitat inferred by the fossil record (Olson \& James 1982), severe wind and rain storms during the breeding season (Simon et al. 1997), and potentially inviable eggs related to small population genetics (Stone $\&$ Scott 1985). The relationship between parental investment and nest success has not been previously explored, especially in relation to severe weather. 


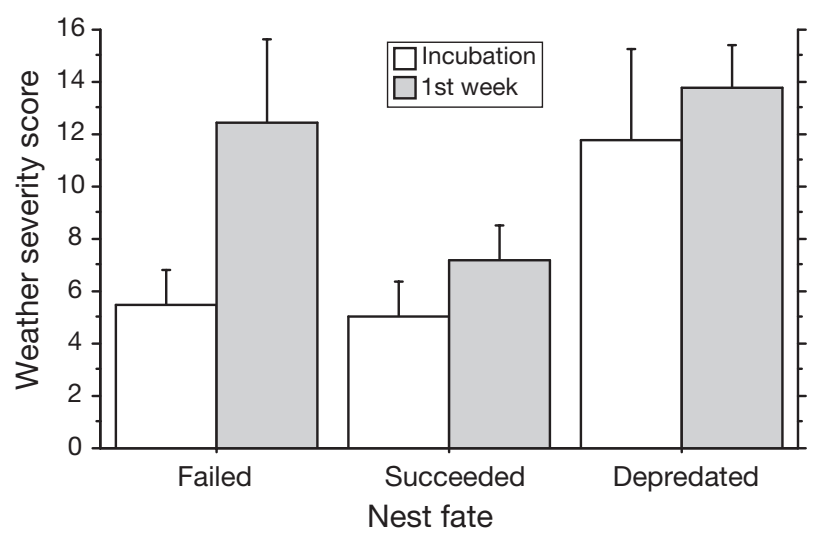

Fig. 4. Pseudonestor xanthophrys. Maximum $( \pm \mathrm{SE})$ weather severity by nest stage and nest fate. Failed nests $(N=7)$ and the one depredated nest had significantly more severe weather during the first week of brooding than successful nests $(\mathrm{N}=4)$

Most Maui parrotbill nests with eggs were found on the rodent removal grid (Malcolm et al. 2008). This pattern was repeated during the 2009 breeding season. Thus, rodent reduction may be improving parrotbill nest success (see VanderWerf 2009). However, at the end of the 2009 breeding season, counts of fledged young ha $\mathrm{h}^{-1}$ were similar at both sites, suggesting that the grid used for rodent control at HR3 may facilitate finding nests.

We documented that Maui parrotbills abandon their nests during severe weather, especially when temperatures are coldest (January to March). During severe weather adults are probably forced to abandon breeding to maintain their own body condition. Variation in the timing of winter storms may be selecting for the long breeding season exhibited by Maui parrotbills. Female, male, and parental investment variables played a significant role in predicting nest fate in Maui parrotbills. In all analyses there was a strong pair effect because $75 \%$ of the successful nests were associated with a single pair.

Female investment was lower at failed nests than at successful nests. Time spent away from nests exposed eggs to ambient temperatures which were cool (2 to $13^{\circ} \mathrm{C}$ ) during the day and dropped below freezing during some winter storms. Prolonged periods of rain in combination with strong winds may force females off the nest to forage, resulting in the death of eggs or young nestlings. Male provisioning during all phases of nesting was highly variable, due to observational constraints. Some provisioning of females takes place off the nest, and these feedings could have been missed. There could also be important differences in the quality of meals brought by males that we were unable to document. Parental feeding of nestlings at failed nests was lower than at successful nests. Similar to reduced incubation, inclement weather may have resulted in parents allocating time to meet their own caloric requirements rather than feeding their chick.

Male song rates may be a function of intrinsic differences such as age or social status or simply a trait of individuals differing consistently (Nowicki et al. 2002, Hyman et al. 2004). Independent of rate, males typically vocalized after bringing food to the nest, presumably to reinforce social bonds.

Maui parrotbill nest success for 2006 to 2008 averaged $39 \%$. Since 1993 and including the 2009 breeding season, MFBRP has monitored 41 Maui parrotbill nests known to have had an egg; 14 of these produced fledglings (34\%; MFBRP unpubl. data). This percentage is not necessarily representative of productivity because pairs renest. In the future, MFBRP will focus on estimating the percentage of pairs that fledge a chick as a measure of productivity. For example, in 2009, 27 pairs were found in the study area; 15 fledglings were associated with these pairs, yielding $55 \%$ as an estimate of Maui parrotbill productivity, a substantially different estimate from nest success. Ultimately, reproductive success in Maui parrotbills depends on the ability of both parents to feed their single chick sufficiently to independence. This aspect of Maui parrotbill life history has yet to be adequately investigated and as a consequence we have a limited understanding of the species' juvenile survival and recruitment rates in the wild.

This work has several implications for the recovery of this endangered species. Since pairs renest, and nests with chicks younger than 1 wk old have low success during winter storms, collection of a small number of eggs or nestlings up to $1 \mathrm{wk}$ old early in the breeding season is unlikely to have negative consequences for Maui parrotbill productivity. However, this should not be done when weather conditions actually support reproduction early in the season. Our findings also suggest that playing male songs to captive-reared Maui parrotbills may be important. Konishi (1985) found that juvenile songbirds with no adult mentor failed to develop normal songs. Given the cohesion of Maui parrotbill family groups, which appears to be mediated by vocalizations, translocation of family groups may be more successful than the translocation of unrelated birds. Finally, supplemental feeding might reduce the time females spend away from the nest and result in higher survival of early or storm-threatened nests. Supplemental food increased nest success in Florida scrub jays Aphelocoma coerulescens (Schoech et al. 2008), and Heath et al. (2008) increased annual fecundity in San Clemente loggerhead shrikes Lanius ludovicianus mearnsi with food additions. Given the nuances of climate change and recovery plan goals to translocate Maui parrotbills to the drier leeward side of east Maui, a better understanding of parental behavior after fledging and up to the dispersal of the young birds is also needed. 
Acknowledgements. We thank field research assistants for suffering long rainy days hiking rough and steep terrain in search of cryptic Maui parrotbill nests at Hanawi. Without their motivation and dedication these analyses would not have been possible. We thank A. Lieberman, R. Switzer, and A. Poopatanapong for sharing their assessments of Maui parrotbill captive breeding, and K. Iknayan for GIS work for Fig. 1. We thank the following organizations whose personnel, land, and funding make our conservation research possible: Haleakala National Park, Hawaii Department of Land and Natural Resources, University of Hawaii and US Fish and Wildlife Service (USFWS). MFBRP holds USFWS permits to band endangered birds on Maui and follows the Institutional Animal Care and Use Committee (IACUC) protocol no. 97-019 for ethical treatment of animals in research. Finally, we thank staff at the Pacific Cooperative Studies Unit for their administrative oversight of MFBRP.

\section{LITERATURE CITED}

Heath SR, Kershner EL, Cooper DM, Lynn S and others (2008) Rodent control and food supplementation increase productivity of endangered San Clemente loggerhead shrikes (Lanius ludovicianus mearnsi). Biol Conserv 141: 2506-2515

Hyman J, Hughes M, Searcy WA, Nowicki S (2004) Individual variation in the strength of territory defense in male song sparrows: correlates of age, territory tenure and neighbor aggressiveness. Behaviour 141:15-27

Jacobi JD, Scott JM (1985) Status, research, and management needs of the native Hawaiian biota. In: Stone CP, Scott JM (eds) Hawaii's terrestrial ecosystems: preservation and management. Cooperative National Park Resources Studies Unit, Honolulu, HI, p 3-22

Konishi M (1985) Birdsong: from behaviour to neuron. Annu Rev Neurosci 8:125-170

Kuehler C, Kuhn M, Kuhn J, Lieberman A, Harvey N, Rideout B (1996) Artificial incubation, hand-rearing, behavior and release of common amakihi (Hemignathus virens virens): surrogate research for restoration of endangered Hawaiian forest birds. Zoo Biol 15:541-553

Malcolm TR, Swinnerton KJ, Groombridge JJ, Sparklin BD, Brosius CN, Vetter JP, Foster JT (2008) Ground-based rodent control in a remote Hawaiian rainforest on Maui. Pac Conserv Biol 14:206-214

Mounce HL (2008) What threat do native avian predators pose to Hawaiian honeycreepers? Two cases of predations by pueo (Asio flammeus sandwichensis). Elepaio 68:19-26

Editorial responsibility: Jim Groombridge, Canterbury, UK
Nowicki S, Searcy WA, Krueger T, Hughes M (2002) Individual variation in response to simulated territorial challenge among territory-holding song sparrows. J Avian Biol 33: 253-259

Olson SL, James HF (1982) Prodromus of the fossil avifauna of the Hawaiian Islands. Smithsonian Contributions to Zoology no. 365, Smithsonian Institution Press, Washington, DC

Pärt T, Doligez B (2003) Gathering public information for habitat selection: prospecting birds cue on parental activity. Proc R Soc Lond B 270:1809-1813

SAS Institute (2008) JMP 8. SAS Institute, Cary, NC, available at www.jmp.com

Schlossberg SR, Ward MP (2004) Using conspecific attraction to conserve endangered birds. Endang Species Update 21: $132-138$

Schoech SJ, Bridge ES, Boughton RK, Reynolds SJ, Atwell JW, Bowman R (2008) Food supplementation: a tool to increase reproductive output. A case study in the threatened Florida scrub-jay. Biol Conserv 141:162-173

Scott JM, Mountainspring S, Ramsey FL, Kepler CB (1986) Forest bird communities of the Hawaiian Islands: their dynamics, ecology, and conservation. Studies in avian biology, Vol 9. Allen Press, Lawrence, KS

Simon JC, Baker PE, Baker H (1997) Maui parrotbill (Pseudonestor xanthophrys) In: Poole A, Gill F (eds) The birds of North America, no. 311. The Birds of North America, Philadelphia, PA, p 1-15

Simon JC, Pratt TK, Berlin KE, Kowalsky JR (2000) Reproductive ecology of the Maui parrotbill. Wilson Bull 112: $482-490$

Stamps JA, Swaisgood RR (2007) Someplace like home: experience, habitat selection and conservation biology. Appl Anim Behav Sci 102:392-409

Stone CP, Scott JM (1985) Hawaii's terrestrial ecosystems: preservation and management. Cooperative National Park Resources Studies Unit, Honolulu, HI, p 298-371

Swaisgood RR (2007) Current status and future directions of applied behavioral research for animal welfare and conservation. Appl Anim Behav Sci 102:139-162

Tweed EJ, Foster JT, Woodworth BL, Monahan BB, Kellerman JL, Lieberman A (2006) Breeding biology and success of a reintroduced population of the Critically Endangered puaiohi (Myadestes palmeri). Auk 123:753-763

US Fish and Wildlife Service (USFWS) (2006) Revised recovery plan for Hawaiian forest birds Region 1. USFWS, Portland, OR

VanderWerf EA (2009) Importance of nest predation by alien rodents and avian poxvirus in conservation of Oahu elepaio. J Wildl Manag 73:737-746

Submitted: April 14, 2009; Accepted: March 4, 2010

Proofs received from author(s): April 22, 2010 